\title{
Potentiometric Sensor for Determination of Tramadol Hydrochloride in Pharmaceutical Preparations and Biological Fluids
}

\author{
Hazem M. Abu Shawish ${ }^{1 *}$, Ayoub R. Al-Dalou${ }^{1}$, Nasser Abu Ghalwa ${ }^{2}$ and Anwar A. Abou Assi ${ }^{3}$ \\ ${ }^{1}$ Chemistry Department, College of Sciences, Al-Aqsa University, Gaza, Palestine \\ ${ }^{2}$ Chemistry Department, Al-Azhar University, Gaza, Palestine \\ ${ }^{3}$ Ministry of Agriculture, laboratory of pesticide
}

\begin{abstract}
A potentiometric tramadol-selective electrode based on the ion-association of tramadol hydrochloride (TDCl) with phosphomolybdic acid (TD-PM) is developed. The electrode exhibits a Nernstian slope of $58.3 \pm 0.7 \mathrm{mV} /$ decade for tramadol ions in the concentration range $2.0 \times 10^{-6}-1.0 \times 10^{-1} \mathrm{M}$ with the limit of detection of $1.3 \times 10^{-6} \mathrm{M}$. The electrode has a fast and stable response time 5-8 s, good reproducibility and it can be used in $\mathrm{pH}$ range of 1.8-6.1. The present electrode show good discrimination of tramadol hydrochloride from several inorganic, organic ions, sugars and some common drug excipients. These characteristics of the electrode enable it to be used successfully for determination of tramadol hydrochloride in its pharmaceutical preparations and biological fluids (urine and milk).
\end{abstract}

Keywords: Tramadol hydrochloride; Ion-selective electrode; Potentiometry; Ppharmaceutical analysis

\section{Introduction}

In recent years, the potentiometric membrane sensors have been widely used in pharmaceutical analysis. [1-3]. This is mainly because of low cost, simple design, wide linear concentration range, low detection limit, adequate selectivity, high accuracy, and applicability of the selective electrodes to colored and turbid solutions [4].

Tramadol hydrochloride, (1RS,2RS)-2-[(dimethylamino) methyl]-1(3-methoxyphenyl) cyclohexanol $\mathrm{HCl}$ (Figure 1), is a centrally acting opioid analgesic in wide spread clinical use throughout the world. It is a synthetic analogue of codeine but has a relatively low affinity for opiate receptors and has not been classified as a controlled substance [5]. Few analytical methodologies, for determination of tramadol in pharmaceutical dosage forms were proposed. They are mainly based on spectrophotometry, HPLC, capillary isotachophoresis [6] and potentiometry [7-11]. Only a few reports [7-11] have been devoted to the construction of ion selective electrodes for tramadol hydrochloride. However, most of these electrodes have not been very fruitful as the developed electrodes have either one, two, or in some cases, all of the following problems, (1) high detection limit, (2) a narrow working concentration range, (3) long response time, (4) serious interferences from various cations, sugars, and amino acids.

This work describes the construction, performance characteristics and analytical application of a novel tramadol ionselective sensor based on ion-association of tramadol hydrochloride with phosphomolybdic acid as electroactive materials and dibutyl phthalate as a plasticizer. The electrode presented in this paper shows

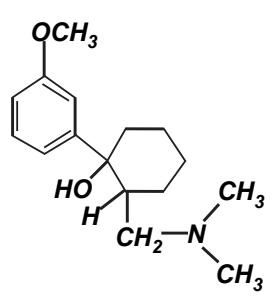

. $\mathrm{HCl}$

Figure 1: The chemical structure of tramadol hydrochloride. a wide concentration range, low limit of detection, good Nernstain slope and high selectivity over a wide variety of other cations.

\section{Material and Methods}

\section{Chemicals}

Tramadol hydrochloride TDCl was obtained from Pharmacare LTD company (Ramallah- Palestine). The pharmaceutical preparations containing TDCl (Tramal, tablets, capsules, drops and ampoules) were obtained from local drug stores. 2-nitrophenyl octyl ether (2-NPOE), dioctyl phthalate (DOP), dibutyl phthalate (DBP), tris(2-ethylhexyl) phosphate (TEPh), dioctyl sebacate (DOS), tributyl phosphate (TBPh) and dibutyl butyl phosphonate (DBBPh) as well as metal salts were purchased from Aldrich and used as received. Phosphomolybdic acid (PMA) were obtained from Sigma.

\section{Apparatus}

Potentiometric measurements were carried out with a digital millivoltmeter (SR-MUL-3800). pH measurements were made with a digital $\mathrm{pH}$ meter (Wissenschaftlich-Technische Werkstatten $\mathrm{GmbH}$ (WTW)- Germany) under stirring conditions at room temperature $\left(25.0 \pm 1.0^{\circ} \mathrm{C}\right)$.

The performance of the electrode was investigated by measuring the emfs of TD solutions with a concentration range of $10^{-7}-10^{-1} \mathrm{M}$ by serial dilution. Each solution was stirred and the potential reading was recorded when it became stable, and plotted as a logarithmic function of TD cation activities.

*Corresponding author: Hazem M. Abu Shawish, Chemistry Department College of Sciences, Al-Aqsa University, Gaza, Palestine, E-mail: hazemona1@ yahoo.co.uk

Received August 25, 2010; Accepted September 26, 2010 Published September 28, 2010

Citation: Abu Shawish HM, Al-Dalou AR, Abu Ghalwa N, Abou Assi AA (2010) Potentiometric Sensor for Determination of Tramadol Hydrochloride in Pharmaceutical Preparations and Biological Fluids. Pharm Anal Acta 1:103. doi:10.4172/2153-2435.1000103

Copyright: (c) 2010 Abu Shawish HM, et al. This is an open-access article distributed under the terms of the Creative Commons Attribution License, which permits unrestricted use, distribution, and reproduction in any medium, provided the original author and source are credited. 


\section{Preparation of ion-pair}

An ion-pair was made from tramadol hydrochloride (TD) with phosphomolybdic acid (PMA) according to a previously reported method [7]. This ion-pair was used as the active substance for preparing the PVC membrane electrode of tramadol hydrochloride.

\section{Preparation of the electrode}

The membranes were prepared as previously described [12]. In each case, after curing, a small disk $(7.5 \mathrm{~mm})$ was punched from the cast film and mounted on the body of a homemade electrode body. The electrode TD-PM was filled with a solution that is $10^{-1} \mathrm{M} \mathrm{NaCl}$ and $10^{-2} \mathrm{M} \mathrm{TDCl}$ and preconditioned by soaking in $10^{-3} \mathrm{M} \mathrm{TDCl}$.

\section{Selectivity coefficient determination}

Separate solution method (SSM) and the Matched Potential Method (MPM) [13] were employed to determine the selectivity coefficients of the potentiometric sensor towards different species.

In the SSM, the potential of a cell comprising a working electrode and a reference electrode is measured in two separate solutions, one containing the drug ions, $\mathrm{E}_{1}$, and the other containing the interferent ions $(J), E_{2}$, and $S$ is the slope of the calibration graph. These values were used to calculate the selectivity coefficient from the following equation:

$$
\log K_{\text {Drug }, J^{Z+}}^{\text {pot }}=\frac{E_{2}-E_{1}}{S}+\log [\operatorname{Drug}]-\log \left[J^{Z+}\right]^{1 / z}
$$

In MPM, specified amounts of TDCl in the range of $2 \times 10^{-4}$ to $2 \times 10^{-5}$ $\mathrm{M}$ were added to a reference solution of $\mathrm{TDCl}$, and the corresponding potential change $(\Delta \mathrm{E})$ was measured. In a separate experiment, $1.0 \mathrm{x}$ $10^{-1} \mathrm{M}$ of the interfering ion $(\mathrm{J})$ was successively added to an identical reference solution until the change in potential matched the $\Delta \mathrm{E}$ value. The values of were then calculated using the following equation:

$$
\log K_{\text {Drug }, J^{z+}}^{\text {pot }}=\frac{\mathrm{a}_{\text {Drug }}}{\mathrm{a}_{J}}
$$

Where the $a_{j}$ is the activity of the added interferent.

\section{Sample preparation}

Tramadol hydrochloride was determined in different formulations (100mg TDCl/capsule, $100 \mathrm{mg} \mathrm{TDCl} /$ tablet, $100 \mathrm{mg} \mathrm{TDCl} / 2 \mathrm{~mL}$-ampoule and $100 \mathrm{mg} \mathrm{TDCl} / 1 \mathrm{~mL}$ Tramal drops).

Samples of tramadol hydrochloride (ampoules, drops, capsules and tablets) ranging from $5.0 \times 10^{-6}$ to $1.0 \times 10^{-3} \mathrm{M}$ TDCl were determined by the standard addition, potentiometric titration, and the calibration curve methods respectively. $1.5 \mathrm{~mL}$-ampoule or $5 \mathrm{~mL}$ of drops solution were transferred to a $50 \mathrm{~mL}$ volumetric flask and diluted to the mark with distilled water. 3 tablets or capsules were powdered and homogenized as described previously [14]. A portion of the powdered mass equivalent to about $150.0 \mathrm{mg}$ of TDCl was accurately weighed and dissolved in $50 \mathrm{~mL}$ of distilled water. This procedure produced $0.01 \mathrm{M}$ solutions of tramadol in these preparations (ampoules, drops and tablets or capsules). Different volumes of these solutions equivalent to $5.0 \times 10^{-6}$ to $2.5 \times 10^{-3} \mathrm{M}$ were taken and analysed by the above methods using the present electrodes. Each analysis was repeated 5 times.

\section{Sample analysis}

The standard addition method in which small increments (10$100 \mu \mathrm{l})$ of $(0.1 \mathrm{~mol} \mathrm{~L}-1) \mathrm{TDCl}$ solution were added to $50.0 \mathrm{~mL}$ aliquot- samples of various concentrations $\left(5.0 \times 10^{-6}\right.$ to $\left.2.5 \times 10^{-3} \mathrm{M}\right) \mathrm{TDCl}$ was applied. The change in potential at $\left(25 \pm 0.1^{\circ} \mathrm{C}\right)$ was recorded after each increment and these data were used to calculate the concentration of $\mathrm{TDCl}$ in the drug samples using the following equation.

$$
\mathrm{C}_{\mathrm{x}}=\frac{\mathrm{C}_{\mathrm{x}} \mathrm{XV} \mathrm{s}}{\left(\mathrm{V}_{\mathrm{x}}+\mathrm{V}_{\mathrm{s}}\right) 10^{\Delta E / \mathrm{S}}-\mathrm{V}_{\mathrm{x}}}
$$

where $C_{x}$ is tramadol concentration in the testing sample, $C_{s}$ is the concentration of the standard, $\mathrm{V}_{\mathrm{x}}$ and $\mathrm{V}_{\mathrm{s}}$ are the corresponding volumes, $\mathrm{S}$ is the slope of the electrode response, and $\Delta \mathrm{E}$ is the change in potential [15]. The potentiometric titration of different volumes of $1.0 \times 10^{-3} \mathrm{M}$ and $1.0 \times 10^{-2} \mathrm{M} \mathrm{TDCl}$ solution: $3-10 \mathrm{~mL}$ equivalent to $0.9-30 \mathrm{mg}$, were transferred to a $25 \mathrm{~mL}$ beaker, and titrated with a standard solution of Na-TPB using the prepared TD-PM as indicator electrode. The end points were determined from the S-shaped curve. In the calibration graph method, different amounts of TDCl were added to $50 \mathrm{~mL}$ of water comprising a concentration range from 1.0 $\mathrm{x} 10^{-7}$ to $1.0 \times 10^{-1} \mathrm{M}$ and the potential was the measured recorded using the present electrode. Data were plotted as potential versus logarithm of the $\mathrm{TD}^{+}$activity and the resulting graph was used for subsequent determination of the concentration of drug samples [16].

\section{Analysis of spiked urine and milk samples}

The samples $(5 \mathrm{ml}$ of urine and $10 \mathrm{~mL}$ of humanized cow milk) were spiked with tramadol hydrochloride and left stirred for $5 \mathrm{~min}$, transferred to a $25-\mathrm{mL}$ volumetric flask and completed to the mark with distilled water to give $1.0 \times 10^{-5}$ to $1.0 \times 10^{-4} \mathrm{M} \mathrm{TDCl}$. These solutions were subjected to the standard additions method or the calibration graph method for determination TDCl [12].

\section{Results and Discussion}

The key factor of the applicability of ion-sensitive electrodes, for tramadol cation, is the selectivity to the ion being determined compared to other ingredients of the medicinal forms. Therefore both the scientific and the practical challenge are the basis and the validation of the ways of the selectivity control by varying the membrane composition. Membranes of different compositions were prepared as shown in Table 1.

\section{Electrode characteristics}

In preliminary experiment, membranes with and without ionexchanger were constructed. The membrane with no exchanger showed no measurable response toward $\mathrm{TD}^{+}$, whereas, in the presence of the proposed ion-exchanger TD-PM, the optimized membrane demonstrated Nernstian response and remarkable selectivity for

\begin{tabular}{|c|c|c|c|c|c|c|}
\hline $\mathrm{R}_{(\mathrm{s})}$ & LOD & \multicolumn{2}{|c|}{$\mathrm{S}$} & \multicolumn{3}{|c|}{ Composition (\%) } \\
\hline & & & Plasticizer & PVC & I.P & No. \\
\hline 20 & $6.5 \times 10^{-5}$ & $46 \pm 2.1$ & $53.0(\mathrm{DBP})$ & 47.0 & -- & $1-$ \\
\hline 10 & $6.8 \times 10^{-6}$ & $49 \pm 1.5$ & $53.0(\mathrm{DBP})$ & 46.9 & 0.1 & $2-$ \\
\hline 8 & $4.1 \times 10^{-6}$ & $56 \pm 0.9$ & $53.2(\mathrm{DBP})$ & 46.5 & 0.3 & $3-$ \\
\hline 5 & $1.3 \times 10^{-6}$ & $58 \pm 0.3$ & $53.0(\mathrm{DBP})$ & 46.5 & 0.5 & $4-$ \\
\hline 10 & $2.0 \times 10^{-6}$ & $57 \pm 1.4$ & $53.0(2-\mathrm{NPOE})$ & 46.5 & 0.5 & $5-$ \\
\hline 10 & $2.8 \times 10^{-6}$ & $55 \pm 0.5$ & $53.0(\mathrm{DOP})$ & 46.5 & 0.5 & $6-$ \\
\hline 15 & $6.2 \times 10^{-6}$ & $53 \pm 0.9$ & $53.0(\mathrm{DOS})$ & 46.5 & 0.5 & $7-$ \\
\hline 10 & $3.1 \times 10^{-6}$ & $57 \pm 0.2$ & $53.0(\mathrm{TEPh})$ & 46.5 & 0.5 & $8-$ \\
\hline 23 & $4.1 \times 10^{-5}$ & $47 \pm 2.3$ & 53.0 (DBBPh) & 46.5 & 0.5 & $9-$ \\
\hline
\end{tabular}

I.P: Ion-pair, S: slope (mV/decade), LOD: limit of detection, R(s): response time(s)

Table 1: Composition and slope of calibration curves for TD-PM membrane electrode. 
$\mathrm{TD}^{+}$over several common inorganic and organic cations. Thus, several membranes of varying nature and ratios of ion-exchanger/ $\mathrm{PVC} /$ plasticizer were prepared for the systematic investigation of the membranes compositions. A few membranes with miscellaneous compositions were made and tested. The composition containing $0.5 \%$, of the ion-pair (membrane No. 4) produced the best response as shown in Table 1 . Higher ratios $(>0.5 \%$ ) were insoluble in THF. Membrane with no ion-exchanger has lower sensitivity and selectivity with poor repeatability.

It is well known that the sensitivity and selectivity obtained for a given ion-selective electrode depends not only on the nature of ionophore used, but also significantly on the membrane composition and the properties of the plasticizer. After the evaluation of six solvent mediators (2-NPOE, DOP, DBP, TEPh, DOS, TBPh and DBBPh), it was observed that DBP with relatively moderate viscosity, lipophilicity, molecular weight and low dielectric constant, produced the best results as shown in table 1 and Figure 2 . Therefore, DBP was used as a suitable plasticizer for further studies.

The results, given in Table 1, indicate that sensor no. 4 , composed of 53.0\% DBP, 46.5\% PVC and $0.5 \%$ ion exchanger (TD-PM), gives the best sensitivity, with a Nernstian slope of $58 \pm 0.3 \mathrm{mV} /$ decade and detection limit of $1.3 \times 10^{-6} \mathrm{M}$ over a relatively wide dynamic range $\left(2.0 \times 10^{-6}\right.$ to $\left.1.0 \times 10^{-1} \mathrm{M}\right)$ of $\mathrm{TD}^{+}$ions. Therefore, this composition was used to study various operation parameters of the electrode. The electrochemical performance characteristics of this electrode were systematically evaluated according to the IUPAC recommendations [17].

\section{Response time, reversibility and repeatability of the electrode}

Dynamic response time is an important factor for an ion-selective electrode. In this study, the practical response time was recorded by changing solution with different $\mathrm{TD}^{+}$concentration from $1.0 \times 10^{-5}$ to $1.0 \times 10^{-1} \mathrm{M}$. The static response time of the electrode over the concentration range was $\approx 5 \mathrm{~s}$ as shown in Figure 3. To evaluate the reversibility of the electrode, a similar procedure in the opposite direction was adopted. with measurements performed in the

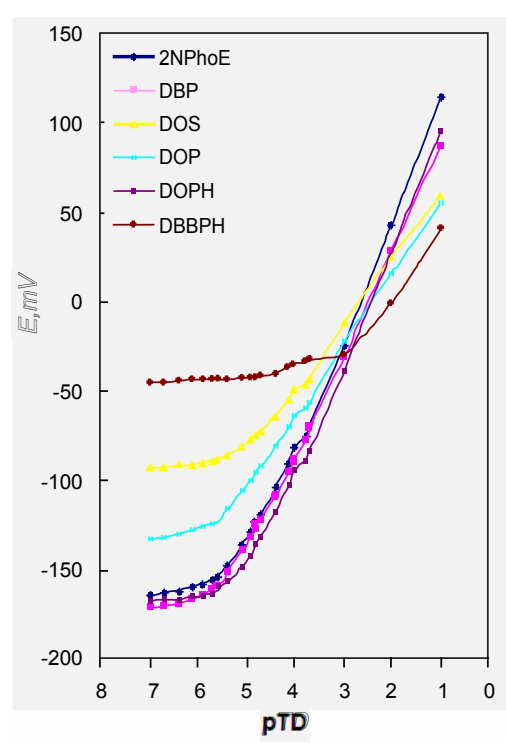

Figure 2: Effect of different plasticizers on the response of TD-PM electrode.

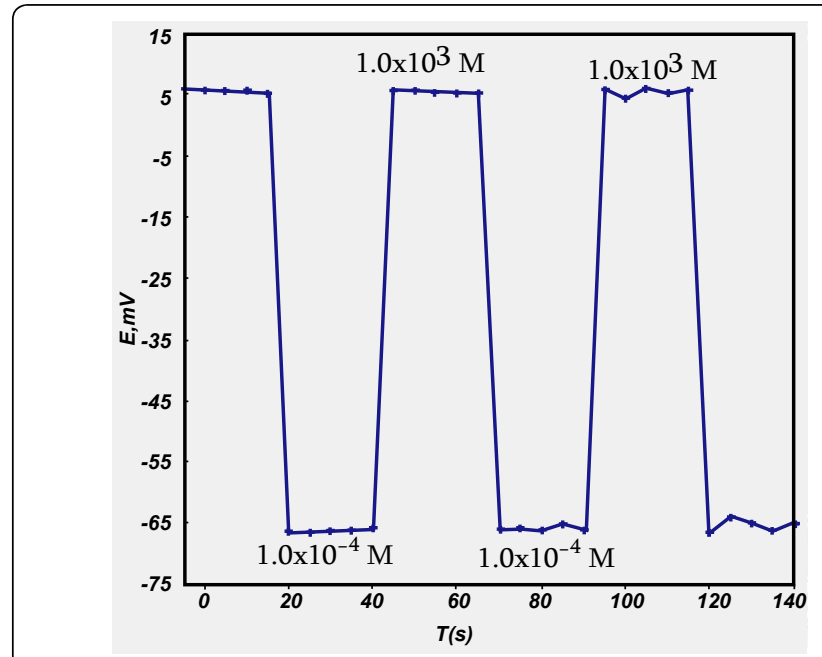

Figure 3: Dynamic response of the TD-PM electrode for several high-to-low sample cycles.

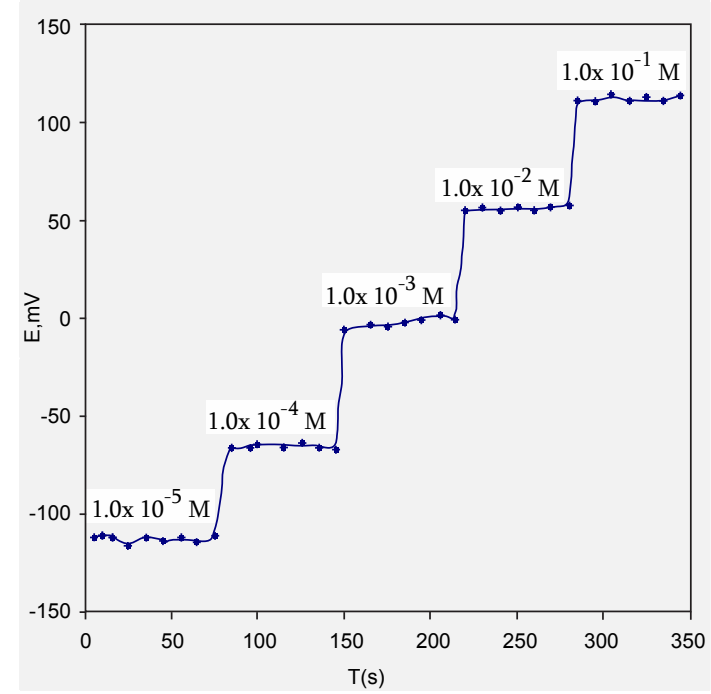

Figure 4: Typical potential-time plot for response of TD-PM electrode.

sequence of high-to-low sample concentrations and the results are shown in Figure 4. It shows that the potentiometric response of the electrode is reversible and the time needed to reach the equilibrium is about $8 \mathrm{~s}$.

The reproducibility of the electrode was also examined by immersing the electrode alternatively in $1.0 \times 10^{-4}$ and $1.0 \times 10^{-2} \mathrm{M}$ of tramadol hydrochloride solutions. The standard deviation of measuring emf for five replicate measurements was found to be 1.582 for $1.0 \times 10^{-4} \mathrm{M}$ solution and 0.305 for $1.0 \times 10^{-2} \mathrm{M}$ solution. This indicates the excellent repeatability of the potential response of the electrode.

\section{Effect of temperature}

To study the thermal stability of the electrode, calibration graphs were constructed at different test solution temperatures of the test solution covering the range $20-60^{\circ} \mathrm{C}$ [18]. The slope, response time, concentration range and the detection limit obtained from the calibration plots as corresponding to each temperature is given in 
Table 3. From Table 2, it is obvious that no appreciable change in the calibration characteristics was observed in the temperature range $20-60^{\circ} \mathrm{C}$.

\section{Lifetime}

A freshly prepared TD-PM electrode can be used after soaking in $1 \times 10^{-3} \mathrm{M}$ of drug solution for at least $15 \mathrm{~min}$. The effect of soaking on the performance of the TD-PM was studied by soaking the electrode in $10^{-3} \mathrm{M}$ solution of tramadol hydrochloride for variable intervals of time starting from 30 min reaching 37 days. The slopes of the electrode were observed to show gradual decrease after 30 days. Therefore, The proposed electrode can be used for one month without any considerable change in potential response.

\section{Internal solution effect}

The internal reference solution affected substantially the characteristics of the electrodes. High $\mathrm{NaCl}$ concentrations without $\mathrm{TD}^{+}$ions yielded electrode with no response. The best results in terms of characteristics of the sensor were obtained with an inner solution containing $1.0 \times 10^{-2} \mathrm{M}$ of $\mathrm{TDCl}$ and $1.0 \times 10^{-1} \mathrm{M} \mathrm{NaCl}$ solution. These results might be due to the fact that the Donnan equilibrium was reached at the interface membrane/inner solution

\begin{tabular}{|c|c|c|c|c|}
\hline $\mathrm{T}(\mathrm{c})$ & $\mathrm{S}$ & C.R. & LOD & $\mathrm{R}(\mathrm{s})$ \\
\hline 20 & $57 \pm 0.8$ & $2.2 \times 10^{-6}-1.0 \times 10^{-1}$ & $1.7 \times 10^{-6}$ & 5 \\
\hline 25 & $58 \pm 0.3$ & $2.0 \times 10^{-6}-1.0 \times 10^{-1}$ & $1.3 \times 10^{-6}$ & 5 \\
\hline 30 & $58 \pm 0.7$ & $2.0 \times 10^{-6}-1.0 \times 10^{-1}$ & $1.3 \times 10^{-6}$ & 7 \\
\hline 35 & $57 \pm 1.1$ & $2.8 \times 10^{-6}-1.0 \times 10^{-1}$ & $1.7 \times 10^{-6}$ & 7 \\
\hline 40 & $56 \pm 0.9$ & $3.1 \times 10^{-6}-1.0 \times 10^{-1}$ & $2.1 \times 10^{-6}$ & 8 \\
\hline 45 & $56 \pm 0.3$ & $3.1 \times 10^{-6}-1.0 \times 10^{-1}$ & $2.3 \times 10^{-6}$ & 7 \\
\hline 50 & $56 \pm 1.1$ & $3.5 \times 10^{-6}-1.0 \times 10^{-1}$ & $2.5 \times 10^{-6}$ & 7 \\
\hline 60 & $55 \pm 0.7$ & $3.8 \times 10^{-6}-1.0 \times 10^{-1}$ & $2.5 \times 10^{-6}$ & 10 \\
\hline
\end{tabular}

$\mathrm{T}(\mathrm{c})$ : temperature, $\mathrm{S}$ : slope ( $\mathrm{mV} /$ decade), C.R.: concentration range (M) LOD: limit of detection (M), R(s): response time(s)

Table 2: characteristics of TD-PM electrode at different temperature.

\begin{tabular}{|c|c|c|}
\hline Interfering ions & $\mathrm{MPM}$ & $\mathrm{SSM}$ \\
\hline $\mathrm{K}^{+}$ & $1.2 \times 10^{-3}$ & $2.8 \times 10^{-3}$ \\
\hline $\mathrm{Na}^{+}$ & $9.6 \times 10^{-5}$ & $5.5 \times 10^{-3}$ \\
\hline $\mathrm{Co}^{2+}$ & $7.5 \times 10^{-4}$ & $3.5 \times 10^{-3}$ \\
\hline $\mathrm{Li}^{2+}$ & $5.7 \times 10^{-4}$ & $2.9 \times 10^{-3}$ \\
\hline $\mathrm{Ni}^{2+}$ & $6.5 \times 10^{-4}$ & $3.8 \times 10^{-3}$ \\
\hline $\mathrm{Mg}^{2+}$ & $5.4 \times 10^{-4}$ & $8.7 \times 10^{-4}$ \\
\hline $\mathrm{Ca}^{2+}$ & $9.5 \times 10^{-4}$ & $4.1 \times 10^{-3}$ \\
\hline $\mathrm{Cu}^{2+}$ & $8.4 \times 10^{-4}$ & $3.5 \times 10^{-3}$ \\
\hline $\mathrm{Zn}^{2+}$ & $4.4 \times 10^{-4}$ & $2.8 \times 10^{-3}$ \\
\hline $\mathrm{Cr}^{3+}$ & $7.2 \times 10^{-4}$ & $1.6 \times 10^{-2}$ \\
\hline Ampicilline sodium & $4.5 \times 10^{-4}$ & $3.9 \times 10^{-3}$ \\
\hline Diclophinic sodium & $2.6 \times 10^{-4}$ & $6.9 \times 10^{-5}$ \\
\hline Captopril & $5.5 \times 10^{-4}$ & $3.3 \times 10^{3}$ \\
\hline Spiramycine & $1.8 \times 10^{-3}$ & $1.7 \times 10^{-2}$ \\
\hline Dioctylsulfosuccinate & $4.5 \times 10^{-4}$ & $9.6 \times 10^{-4}$ \\
\hline Spectinomycine Hcl & $8.9 \times 10^{-4}$ & $1.5 \times 10^{-3}$ \\
\hline D-Fractose & - & $2.5 \times 10^{-5}$ \\
\hline D- Galactose & - & $5.5 \times 10^{-5}$ \\
\hline Maltose & - & $6.9 \times 10^{-5}$ \\
\hline Glucose & - & $2.8 \times 10^{-5}$ \\
\hline Ascorbic acid & $5.4 \times 10^{-4}$ & $3.0 \times 10^{-4}$ \\
\hline L-Histidine & $4.5 \times 10^{-4}$ & $1.9 \times 10^{-3}$ \\
\hline Glycine & $4.9 \times 10^{-4}$ & \\
\hline
\end{tabular}

Table 3: Selectivity coefficient for TD-PM electrode and an electrical potential was generated (Donnan potential) that is necessary to develop the membrane potential. This was probably not the case when the inner solution contained $\mathrm{NaCl}[19]$.

\section{Selectivity of the electrodes}

The potentiometric selectivity coefficient of an electrode, as one of the most important characteristics, is defined by its relative response for the primary ion over the other ions present in the solution [20]. The separate solution method (SSM) is recommended by IUPAC to determine the selectivity coefficient of the ISE [13]. SSM is based on Nickolsky-Eisenman equation. However, it has been shown that this method suffers some limitations in terms of the values for ions of unequal charges, a non-Nernstain behavior of interfering ions [21].

Therefore another method named the "matched potential method (MPM)" was recommended especially when the primary ion and/or the interfering ion dissatisfy with the Nernst response or when the involved ions are unequal in charge [22]. The resulting values, presented in Table 3, show that these sensors display significantly high selectivity for tramadol over many common organic and inorganic compounds, drugs, sugars, amino acids as well as some anions.

In pharmaceutical analysis, it is important to test the selectivity toward the excipients and the fillers added to the pharmaceutical preparations. Tramadol pharmaceutical formulations, mainly tablets, contain common excipients such as lactose, glucose, sucrose, starch, stearic acid, magnesium stearate and microcrystalline cellulose. The interference of some of these excipients was explored and measured. It is found that they cause minor effect on the function of the electrode as shown in Table 4. It is worth mentioning that measurements performed on tablets showed accurate results as high as $98.5 \%$ indicating that these excipients made negligible effect on the performance of the electrode. Comparing the selectivity coefficient values obtained for the investigated electrodes in both SSM and MPM methods collected in Table 3, makes obvious that there is a measurable difference between the values for each interfering ion obtained in both cases. The values of selectivity coefficients obtained using MPM method are more reliable. It is noticed that the results of selectivity tests on interfering monovalent ions are similar to those of tramadol ion. However, the bivalent and trivalent cations produce different results from the two methods. This is reasonable considering that the SSM depends on the charge and gives inaccurate results.

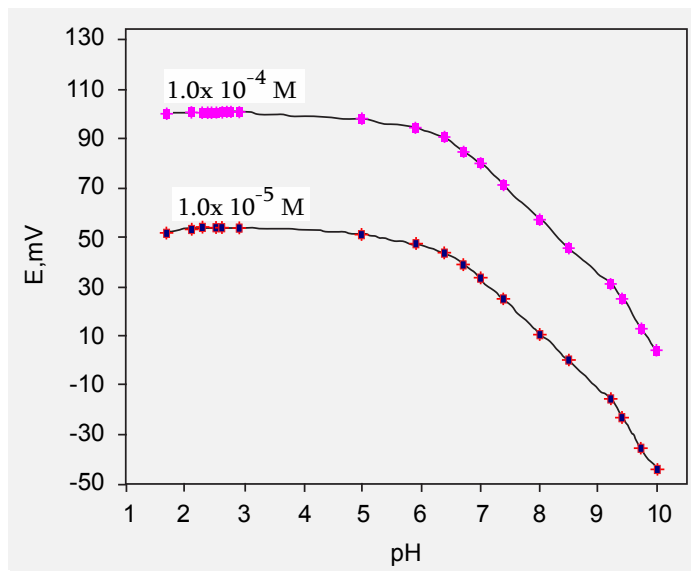

Figure 5: Effect of $\mathrm{pH}$ on response of TD-PM response. 


\begin{tabular}{|c|c|c|c|c|c|}
\hline \multirow{2}{*}{ samples } & \multicolumn{2}{|l|}{ M } & \multirow[b]{2}{*}{$X \pm$ S.E } & \multirow[b]{2}{*}{ F-values } & \multirow[b]{2}{*}{ t-Values } \\
\hline & Taken & Found & & & \\
\hline \multicolumn{6}{|l|}{ Capsule } \\
\hline $\mathrm{P}$ & $1.00 \times 10^{-2}$ & $1.03 \times 10^{-2}$ & $103.0 \pm 0.035$ & 3.25 & 1.25 \\
\hline$S$ & $5.00 \times 10^{-6}$ & $4.88 \times 10^{-6}$ & $97.6 \pm 0.019$ & 2.54 & 2.13 \\
\hline $\mathrm{C}$ & $7.50 \times 10^{-5}$ & $7.41 \times 10^{-4}$ & $98.8 \pm 0.079$ & 1.58 & 2.55 \\
\hline \multicolumn{6}{|l|}{ Ampoule } \\
\hline$P$ & $1.00 \times 10^{-3}$ & $1.01 \times 10^{-3}$ & $101.0 \pm 0.058$ & 1.54 & 1.88 \\
\hline$S$ & $1.50 \times 10^{-5}$ & $1.52 \times 10^{-5}$ & $101.3 \pm 0.071$ & 2.11 & 1.23 \\
\hline $\mathrm{C}$ & $1.00 \times 10^{-4}$ & $9.91 \times 10^{-5}$ & $99.1 \pm 0.035$ & 3.12 & 1.15 \\
\hline \multicolumn{6}{|l|}{ Tablet } \\
\hline $\mathrm{P}$ & $5.00 \times 10^{-4}$ & $4.93 \times 10^{-4}$ & $98.6 \pm 0.012$ & 3.56 & 2.45 \\
\hline$S$ & $1.00 \times 10^{-5}$ & $1.00 \times 10^{-5}$ & $100.0 \pm 0.015$ & 2.89 & 1.58 \\
\hline $\mathrm{C}$ & $2.00 \times 10^{-5}$ & $2.02 \times 10^{-5}$ & $101.0 \pm 0.013$ & 2.77 & 1.11 \\
\hline \multicolumn{6}{|l|}{ Drops } \\
\hline $\mathrm{P}$ & $1.00 \times 10^{-3}$ & $1.02 \times 10^{-3}$ & $102.0 \pm 0.045$ & 3.87 & 2.51 \\
\hline$S$ & $1.00 \times 10^{-5}$ & $9.75 \times 10^{-6}$ & $97.5 \pm 0.020$ & 3.01 & 2.79 \\
\hline$C$ & $5.00 \times 10^{-4}$ & $5.02 \times 10^{-4}$ & $100.4 \pm 0.011$ & 1.59 & 1.77 \\
\hline \multicolumn{6}{|l|}{ urine } \\
\hline$S$ & $1.00 \times 10^{-5}$ & $1.03 \times 10^{-6}$ & $103.0 \pm 0.044$ & 4.21 & 3.24 \\
\hline C & $1.00 \times 10^{-4}$ & $9.72 \times 10^{-5}$ & $97.2 \pm 0.020$ & 3.98 & 3.18 \\
\hline \multicolumn{6}{|l|}{ milk } \\
\hline$S$ & $1.00 \times 10^{-5}$ & $1.02 \times 10^{-5}$ & $102.0 \pm 0.032$ & 3.88 & 3.56 \\
\hline $\mathrm{C}$ & $1.00 \times 10^{-4}$ & $9.62 \times 10^{-5}$ & $96.2 \pm 0.039$ & 4.12 & 3.22 \\
\hline
\end{tabular}

P: potentiometric titration, C: calibration curve, S: standard addition method. The number of replicate measurements $=4$. X \pm S.E.: recovery \pm standard error. R.S.D. relative, standard deviation. The critical value of $F=9.28$ and the critical value of $t=3.707$.

\section{Table 4: Determination of TDCl in different samples.}

However, the MPM gave more accurate ones as it is independent of the charge of the ion.

\section{Effect of $\mathrm{pH}$}

Wide application of an ISE requires the knowledge of the $\mathrm{pH}$ range of the functioning of given electrode. The medium acidity may be affects the state of an ion associate and other membrane components [23]. In order to study the effect of $\mathrm{pH}$ on the performance of the sensor, the potentials were determined at two concentrations $(1.0 \times$ 10-3 and $1.0 \times 10-2 \mathrm{M}$ ) of TD+ ions as a function of $\mathrm{pH}$. The $\mathrm{pH}$ of the solution was varied by the addition of $\mathrm{NaOH}$ and $\mathrm{HCl}$.

As can be seen from the results shown in Figure 5, the potential variation due to $\mathrm{pH}$ change is considered acceptable in the $\mathrm{pH}$ range 1.5-6.5. Nevertheless, at $\mathrm{pH}$ values higher than 6.1 , the potential decreases gradually, which can be attributed to the formation of the free tramadol base in the test solution.

\section{Analytical applications}

The proposed sensor was employed for the assay of tramadol hydrochloride content in tablets, capsules, drops and ampoules by the standard additions, the calibration curve and potentiometric titration methods. The results are satisfactory considering the consistency and low standard deviation as shown in Table 4.

In pharmaceutical analysis, it is important to test the selectivity toward the excipients and the fillers added to the pharmaceutical preparations. Fortunately, such materials mostly do not interfere. This is clear from the results obtained for the pharmaceutical preparations (Table 4) that these excipients do not interfere.

The TD-PM was used as indicator electrode in the potentiometric titration of $\mathrm{TDCl}$ with $\mathrm{NaTPB}$, and the resulting titration curve is shown in Figure 6. As seen, the amount of TD ion can be accurately determined with this electrode.

Tramadol is rapidly and almost completely absorbed after oral administration and has a bioavailability of $65-70 \%$ due to first-pass metabolism. Approximately $10-30 \%$ of the parent drug is excreted unmetabolised in the urine. In addition [24]. The possible risks to the neonates and infants should always be carefully considered, regardless of the fact that usually low drug concentrations may be found in the milk. It is estimated that $0.1 \%$ of the original dose of tramadol passes into milk [25]. Therefore, it is necessary to estimate

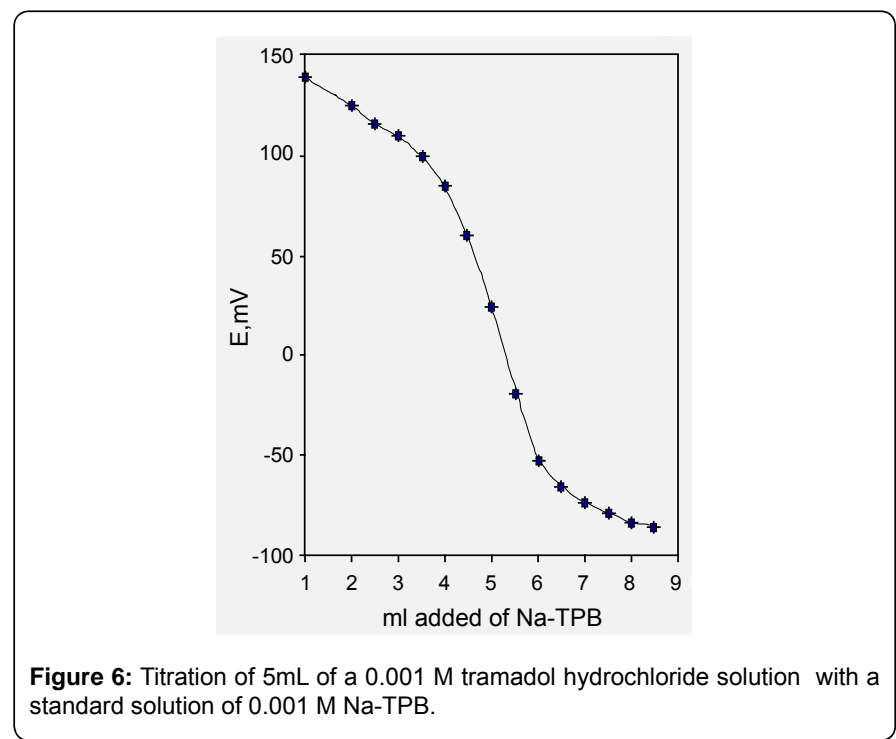


Citation: Abu Shawish HM, Al-Dalou AR, Abu Ghalwa N, Abou Assi AA (2010) Potentiometric Sensor for Determination of Tramadol Hydrochloride in Pharmaceutical Preparations and Biological Fluids. Pharm Anal Acta 1:103. doi:10.4172/2153-2435.1000103

Page 6 of 6

tramadol in various samples such as urine, and humanized milk. Cosequently, a variety of these biological fluids were analyzed for tramadol using the standard addition method with the prepared TDPM electrode.

In the present method TDCl was determined in urine and humanized cow milk samples spiked with known amounts of the drug applying the standard additions technique to overcome the matrix effects in these real samples.

The performance of the method was also assessed by calculation of the $t$ - and F-values in comparison to the official method [26]. Mean values were obtained in a student's $t$ - and $F$-test at $95 \%$ confidence limits for corresponding degrees of freedom [27], and the results showed in table 4 that the calculated $t$ - and $F$-values did not exceed the critical values.

\section{Conclusion}

Tramadol hydrochloride was determined in pharmaceutical products as well as in biological fluids by using a new PVCmembrane electrode. The proposed PVC-electrode based on Dc-PM ion-exchangers as the electroactive compounds might be useful detectors and interesting alternatives for the determination of $\left[\mathrm{TD}^{+}\right]$ in different real samples. The sensor displays a Nernstian response of $58 \pm 0.3 \mathrm{mVdecade}^{-1}$, offers a wide linear response range $\left(2.0 \times 10^{-6}\right.$ to $1.0 \times 10^{-1} \mathrm{M}$ ), provides a low detection limit of $1.3 \times 10^{-6} \mathrm{M}$, shows a fast response time $(5 \mathrm{~s})$, and exhibits excellent selectivities from several inorganic, organic ions, sugars and some common drug excipients.

\section{Acknowledgments}

The authors would like to thank Prof. Salman M. Saadeh (The Islamic University, Gaza, Palestine), Prof. Yousry M. Issa, for encouragement, support and providing facilities for research.

\section{References}

1. Abu Shawish MH (2008) Potentiometric Response of Modified Carbon Paste Electrode Based on Mixed Ion-Exchangers. Electroanalysis 20: 491-497.

2. Kormosh Z, Hunka I, Bazel Y (2008) Preparation and Characterization of a Diclofenac Sensitive Electrode Based on a PVC Matrix Membrane. Acta Chim. Slov 55: 261-267.

3. Dimeski G, Badrick T, John AS (2010) Ion Selective Electrodes (ISEs) and interferences-A review. Clinica Chimica Acta 411: 309-317.

4. Bakhtiarzadeh F, AbGhani S (2008) Anion selective electrode formercury(II) basedon mercury(II) complex of poly(4-vinyl pyridine). J Electroanal Chem 624: 139-143.

5. Küçük A, Kadıoğlu Y, Celebi $F$ (2005) Investigation of the pharmacokinetics and determination of tramadol in rabbit plasma by a high-performance liquid chromatography-diode array detector method using liquid-liquid extraction. $J$ Chromatogr B 816: 203-208.

6. Rouini RM, Ardakani YH, Soltani F, Aboul-Enein YH, Foroumadi A (2006) Development and validation of a rapid HPLC method for simultaneous determination of tramadol, and its two main metabolites in human plasma. $J$ Chromatogr B 830: 207-211.

7. Abu-Shawish MH, Abu Ghalwa, N, Zaggout RF, Saadeh MS, Al-Dalou RA, et al. (2010) Improved determination of tramadol hydrochloride in biological fluids and pharmaceutical preparations utilizing a modified carbon paste electrode. Biochem Eng J 48: 237-245.

8. Ganjali RM, Razavi T, Faridbod F, Riahi S, Norouzi P (2009) Application of a new tramadol potentiometric membrane sensor as a useful device for tramado hydrochloride analysis in Pharmaceutical formulation and urine. Curr Pharm Anal 5: 28-33.

9. Wu JY, Shi J, Zhang JH, Zhao KL, Zhang ZP (2005) Preparation and application of an ion-selective electrode by tramadol hydrochloride. Fenxi Shiyanshi 24 : 49-51.

10. Huang CL, Xiu R, Liu ZY, Li YC, Meng CJ (2005) Preparation and application of a doubly coated membrane tramadol ion-selective electrode based on $\mathrm{Ag} / \mathrm{AgCl}$ wire. Fenxi Kexue Xuebao 21: 48-50.

11. Zhong AG (2003) Behavior and application of the tramadol ion selective electrode coated with PVC membrane. Lihua Jianyan Huaxue Fence Phys Test Chem.Anal Part B: Chem Anal 39: 59-60.

12. Ibrahim H, Issa MY, Abu Shawish MH (2005) Potentiometric Flow Injection Analysis of Dicyclomine Hydrochloride in Serum, Urine and Milk. Anal. Chim. Acta 532: 79-88.

13. Umezawa Y, Buhlmann P, Umezawa K, Tohda K, Amemiya S (2000) Potentiometric selectivity coefficients of ion-selective electrodes. Pure Appl Chem 72: 1851-2082.

14. Venkateshwarlu K, Reddy YN, Srisailam K, Rajkumar V, Pai MG (2008) Determination of tramadol in capsules by high performance thin layer chromatography-densitometry. Curr Trends Biotechnol Pharm 2: 421-425.

15. Baumann E (1968) Trace fluoride determination with specific ion electrode Anal Chim Acta 42: 127-132.

16. Mostafa GA (2007) Development and characterization of ion selective electrode for the assay of antimony. Talanta 71: 1449-1454.

17. Buck PR, Lindner E (1994) Recommendations for nomenclature of ion-sensitive electrodes. Pure Appl Chem 66: 2527-2536.

18. Ibrahim H, Issa MY, Abu Shawish MH (2005) Potentiometric flow injection analysis of mebeverine hydrochloride in serum and urine. J Pharm Biomed Anal 36: 1053-1061.

19. Rachidi M, Elharti J, Digua K, Cherrah Y, Bouklouze A (2007) New Polymeric Membrane Electrode for Azithromycin Determination. Anal Lett 40: 53-66.

20. Singh KA, Mehtab S (2007) Calcium(II)-selective potentiometric sensor based on a-furildioxime as neutral carrier. Sens Actuators B 123: 429-436.

21. Chandra S, Agarwal $H$, Singh KC (2007) A highly selective and sensitive thorium (IV) PVC membrane electrode based on a dithio-tetraaza macrocyclic compound. Anal Sci 23: 469-473.

22. Wang XH, Pu MA (2002) A method of determining selectivity coefficients based on the practical slope of ion selective electrodes. Chin Chem Lett 13: 355-358.

23. Kormosh Z, Hunka I, Bazel Y (2008) An electrode immobilized in a graphite matrix with ion pair complex for the determination of diclofenac in pharmaceuticals. J Iran Chem Res 1: 25-32.

24. Patel NB, Sharma N, Sanyal M, Shrivastav SP (2009) An accurate rapid and sensitive determination of tramadol and its active metabolite O-desmethyltramadol in human plasma by LC-MS/MS. J Pharm Biomed Anal 49: 354-366.

25. Kmetec V, Roskar R (2003) HPLC determination of tramadol in human breas milk. J Pharm Biomed Anal 32: 1061-1066.

26. British Pharmacopia (2000) Cambridge University Press, Cambridge vol. 1.

27. Miller CJ, Miller NJ (1984) Statistics for Analytical Chemistry, Ellis Horwood, Chichester, England. 